\title{
Clinical efficacy of adalimumab in Crohn's disease: a real practice observational study in Japan
}

Fuminao Takeshima ${ }^{1 *}$, Daisuke Yoshikawa ${ }^{2}$, Syuntaro Higashi ${ }^{3}$, Tomohito Morisaki ${ }^{4}$, Hidetoshi Oda ${ }^{5}$, Maho Ikeda ${ }^{6}$, Haruhisa Machida ${ }^{7}$, Kayoko Matsushima ${ }^{1}$, Hitomi Minami ${ }^{1}$, Yuko Akazawa', Naoyuki Yamaguchi', Ken Ohnita', Hajime Isomoto ${ }^{1}$, Masato Ueno ${ }^{8}$ and Kazuhiko Nakao ${ }^{1}$

\begin{abstract}
Background: There are few reports of the efficacy of adalimumab (ADA) for clinical remission and preventing postoperative recurrence in Crohn's disease (CD) in Asian real practice settings. We conducted a Japanese multicenter retrospective observational study.

Methods: We evaluated patients with CD who were treated with ADA at 11 medical institutions in Japan to investigate the clinical efficacy of remission up to 52 weeks and the associated factors to achieve remission with a CD Activity Index $(C D A I)<150$. The effects of preventing postoperative recurrence were also evaluated.

Results: In 62 patients, the remission rates were 33.9, 74.2, 75.8, 77.4, and $66.1 \%$ at 0, 4, 12, 26, and 52 weeks, respectively. Although 10 patients discontinued treatment due to primary nonresponse, secondary nonresponse, or adverse events, the ongoing treatment rate at 52 weeks was $83.9 \%$. Comparison of remission and non-remission on univariate analysis identified colonic type and baseline CDAl value as significant associated factors $(P<0.05)$. In 16 patients who received ADA to prevent postoperative recurrence, the clinical remission maintenance rate was $93.8 \%$ and the mucosal healing rate was $64.3 \%$ during a mean postoperative follow-up period of 32.3 months.
\end{abstract}

Conclusions: ADA effectively induced remission and prevented postoperative recurrence in patients with CD in a real practice setting.

Keywords: Adalimumab, Crohn's disease, Preventing postoperative recurrence, Japanese patients, Real practice

\section{Background}

Crohn's disease $(\mathrm{CD})$, an inflammatory bowel disease (IBD), is an intractable disease of unknown etiology [1].

$\mathrm{CD}$ is progressive and markedly impairs patient quality of life due to its associated symptoms such as diarrhea, abdominal pain, fever, and surgery [2-4]. Although there is currently no cure for $\mathrm{CD}$, the inflammatory cytokine tumor necrosis factor- $\alpha$ (TNF- $\alpha$ ) is involved in clinical condition [5], against which anti-TNF- $\alpha$ monoclonal antibody (anti-TNF- $\alpha$ antibody) is highly effective $[6,7]$. For the treatment of $\mathrm{CD}$, infliximab (IFX), a chimeric

\footnotetext{
* Correspondence: ftake@nagasaki-u.ac.jp

${ }^{1}$ Department of Gastroenterology and Hepatology, Graduate School of Biomedical Science, Nagasaki University Hospital, 1-7-1 Sakamoto, Nagasaki City, Nagasaki 852-8501, Japan

Full list of author information is available at the end of the article
}

antibody and infusion drug, first appeared as an antiTNF- $\alpha$ antibody, followed by adalimumab (ADA), a fully humanized antibody and subcutaneous drug. IFX and ADA were highly effective in large-scale studies and have already been widely used worldwide [8-15].

Although the clinical features of CD in Asia is relatively similar to that of North America or Europe, there are some differences such as a higher prevalence of males and ileo-colonic type, less familial clustering, extra-intestinal manifestations, and surgical rates. As for genetics, nucleotide oligomerization domain-2 (NOD2) variants and autophagy-related 16-like 1(ATG16L1) variants, which have been firmly associated with $\mathrm{CD}$ in the West have not been detected in the patients with CD in Asia [16]. Taking account of these differences, the data from Asia is important in spite of the numerous data from West. However, 
ADA received approval later in Asian countries including Japan than in the Europe and US; therefore, there are limited reports on its efficacy in Asian real practice settings [17-20]. Watanabe et al. reported that clinical remission rate at week 4 in the induction therapy was $33.3 \%$. Seventy percentage of patients achieved decrease in $\mathrm{CDAI} \geq 70$ points and the rest was unresponsive at week 4 in the induction therapy [17]. Furthermore, intestinal resection is commonly required in patients with $C D$ and often leads to repeated surgery; thus, it is important to prevent postoperative recurrence $[21,22]$. Recent reports indicated that IFX and ADA effectively prevent postoperative recurrence [23-26]. However, no report to date has demonstrated the ability of ADA to prevent postoperative recurrence in Asia. Under these circumstances, we conducted a multicenter observational study in Japan to evaluate ADA efficacy and safety as well as its ability to prevent postoperative recurrence in patients with $C D$ in real practice settings.

\section{Methods}

\section{Study design}

The Nagasaki observational study of adalimumab is a multicenter retrospective observational study of patients with IBD receiving ADA treatment at a total of 11 medical sites including Nagasaki University Hospital and its related facilities. This study was reviewed and approved by the Nagasaki University Hospital Ethics Committee before its initiation.

\section{Patients}

The study included all patients who received ADA for the treatment of $C D$ at a total of 11 study sites including Nagasaki University Hospital and its related facilities between November 2010 and January 2014. Patients who failed to complete 52 weeks of follow-up due to relocating were excluded from the analysis.

\section{Treatment protocol}

ADA was administered at an initial dose of $160 \mathrm{mg}$ and a second dose of $80 \mathrm{mg}$ with a 2-week induction interval. Thereafter, ADA $40 \mathrm{mg}$ was administered every other week as maintenance therapy. ADA dose intensification was not included in this study because it is not currently approved in Japan.

\section{Data collection}

A shared common database was used to collect demographic and clinical data. Data collected at baseline were sex, age, disease duration, disease extension, history of operation, smoking habits, concomitant fistula or anal lesion, previous infliximab therapy, concomitant medications or elemental diet at baseline, C-reactive protein (CRP) levels, and the Crohn's disease activity index (CDAI) [27].
Clinical activity was evaluated using the CDAI after 4, 12, 26, and 52 weeks of treatment. The date of and reason for ADA discontinuation, requirement of further rescue therapy, and adverse events were also recorded.

\section{Definition}

We defined remission as a $\mathrm{CDAI}<150$. Non-remission was defined as discontinuation due to a lack of efficacy, adverse event, or other reason. In addition, we evaluated the ability of ADA to prevent postoperative recurrence in patients with any recurrence risk factor [28] such as smoking, penetrating disease, history of prior resection, and short disease duration ( $<10$ years) after intestinal resection. Clinical remission was defined as a CDAI $<150$, and mucosal healing was confirmed by a Rutgeerts score of i0 or i1 [29].

\section{Endpoints}

The primary endpoints of the study were rates of clinical remission at $4,12,26$, and 52 weeks in the intention-totreat (ITT) population, and the proportion of patients still receiving ADA therapy at the end of the first year. The secondary endpoints included the maintenance rate of clinical remission and mucosal healing in the patients who received ADA treatment for the prevention of postoperative recurrence.

\section{Statistical analysis}

All efficacy analyses were performed on an ITT basis. Statistical analysis was performed with a Chi-square test or Fisher's exact test for categorical data and Student's $t$-test or the Mann-Whitney $U$-test for continuous variables. Factors identified as having significant differences on univariate analysis were further assessed by multivariate analysis with logistic regression. $P$ values $<0.05$ were considered statistically significant.

\section{Results}

Patient demographics

Of 71 patients who received ADA treatment during the study period, 62 were included in the analysis set, while the other nine were excluded: three who failed to complete follow-up due to transfer to another hospital before 52 weeks, five who missed the CDAI evaluation, and one who intentionally withdrew from treatment due to pregnancy (Fig. 1). The baseline characteristics of the 62 patients are shown in Table 1 . The mean age was 33.1 years, $74.2 \%$ of the patients were men, the median disease duration was 96 months, and $32.3 \%$ of the patients had a disease duration $<2$ years. Prior treatment consisted of IFX in $53.2 \%$ of the patients; of them $33.3 \%$ were on a double IFX dose $(10 \mathrm{mg} / \mathrm{kg})$. The mean baseline CDAI was 185.1 points, and $33.9 \%$ of the patients had a 


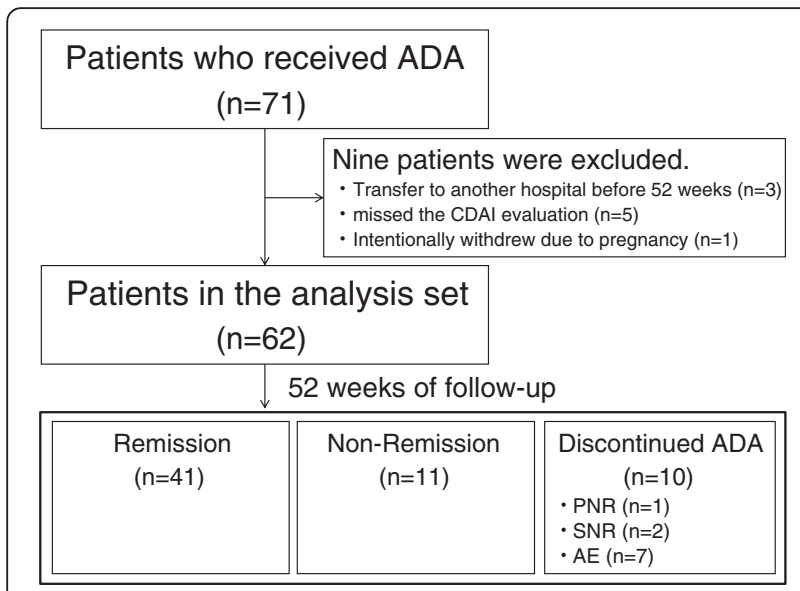

Fig. 1 Flowchart of patient disposition. ADA; adalimumab, CDAl; Crohn's Disease Activity Index, PNR; primary nonresponse, SNR; secondary nonresponse, $\mathrm{AE}$; adverse event

$\mathrm{CDAI}<150$ before ADA treatment, including those who required a medication switch due to IFX intolerance.

\section{Clinical efficacy}

In all 62 patients, the remission rates were 33.9, 74.2, $75.8,77.4$, and $66.1 \%$ at $0,4,12,26$, and 52 weeks, respectively (Fig. 2a). In the 41 patients whose baseline CDAI was $\geq 150$, the remission rates were $63.4,70.7$, 75.6 , and $56.1 \%$ at $4,12,26$, and 52 weeks, respectively (Fig. 2b). Of the 62 patients, 10 discontinued treatment due to primary nonresponse (PNR) $(n=1)$, secondary nonresponse (SNR) $(n=2)$, or adverse event $(n=7)$. The ongoing ADA treatment rate at 52 week was $83.9 \%$ (Fig. 3).

\section{Efficacy predictor}

An univariate analysis was performed to compare 41 patients who achieved remission at 52 weeks of ADA treatment (remission group) with 21 patients who failed to achieve remission with a CDAI $\geq 150$ or discontinued ADA treatment before 52 weeks (non-remission group) (Table 2). Significant differences between groups were detected only for the colonic type $(P=0.0387)$ and baseline CDAI $(P=0.0236)$. The remission group had a slightly lower median disease duration and included more patients with a disease duration $<2$ years, but the difference was not statistically significant. A multivariate analysis was performed for the two factors, colonic type and baseline CDAI, identified significant differences from the univariate analysis, but both were not found to be significant (Table 3).

\section{Prevention of postoperative recurrence}

The baseline characteristics, presence of risk factors, clinical remission after ADA treatment, and mucosal healing
Table 1 Patients' baseline characteristics

\begin{tabular}{|c|c|}
\hline Patient number & 62 \\
\hline Age (years) & $33.1 \pm 10.3$ \\
\hline Gender (male) & $74.2 \%(46 / 72)$ \\
\hline Disease duration (months) & $96.0(0.0-480.0)$ \\
\hline Disease duration $<2$ years & $32.3 \%(20 / 62)$ \\
\hline \multicolumn{2}{|l|}{ Disease location } \\
\hline Ileo & $14.5 \%(9 / 62)$ \\
\hline Ileocolonic & $74.2 \%(46 / 62)$ \\
\hline Colonic & $11.3 \%(7 / 62)$ \\
\hline Surgery required & $62.9 \%(39 / 63)$ \\
\hline Extra fistula & $34.4 \%(21 / 61)$ \\
\hline Intra fistula & $8.2 \%(5 / 61)$ \\
\hline Perianal disease & $48.4 \%(30 / 62)$ \\
\hline Smoking & $17.3 \%(9 / 52)$ \\
\hline \multicolumn{2}{|l|}{ Concomitant use } \\
\hline 5-Aminosalicylates & $91.9 \%(57 / 62)$ \\
\hline Steroids & $9.7 \%(6 / 62)$ \\
\hline Immunomodulators & $24.2 \%(15 / 62)$ \\
\hline Elemental diet & $62.9 \%(39 / 62)$ \\
\hline \multicolumn{2}{|l|}{ IFX experience } \\
\hline Experience with IFX & $53.2 \%(33 / 62)$ \\
\hline Double dose & $33.3 \%(11 / 33)$ \\
\hline Duration of IFX use (months) & $19.0(1.0-100)$ \\
\hline \multicolumn{2}{|l|}{ Reason for switching } \\
\hline PNR & $6.3 \%(2 / 32)$ \\
\hline SNR & $46.9 \%(15 / 32)$ \\
\hline Intolerance & $43.8 \%(14 / 32)$ \\
\hline Others & $3.1 \%(1 / 32)$ \\
\hline Baseline CDAI (points) & $185.1 \pm 76.4$ \\
\hline Baseline CRP (mg/dL) & $0.74(0.00-6.86)$ \\
\hline
\end{tabular}

Parametric variables are shown as mean \pm standard deviation or median (range)

IFX infliximab, PNR primary nonresponse, SNR secondary nonresponse, CDAI Crohn's Disease Activity Index, CRP C-reactive protein

by endoscopy of the 16 high-risk patients who received ADA treatment for the prevention of postoperative recurrence after intestinal resection are shown in Table 4. Each patient had an average of 2.1 of four recurrence risk factors including smoking, penetrating disease, previous resection, and disease duration $<10$ years. The maintenance rate of clinical remission up to the last observation period (a mean of 32.3 months) was $93.8 \%$ (15/16 patients). Endoscopy was performed in 14 patients at a mean 25.3 months, and mucosal healing was confirmed in $64.3 \%$ (9/14 patients). Clinical remission was confirmed in four of five patients who experienced endoscopic relapse. Of the three patients whose relapse was confirmed with a Rutgeerts score of i3 or i4, two had experience with 

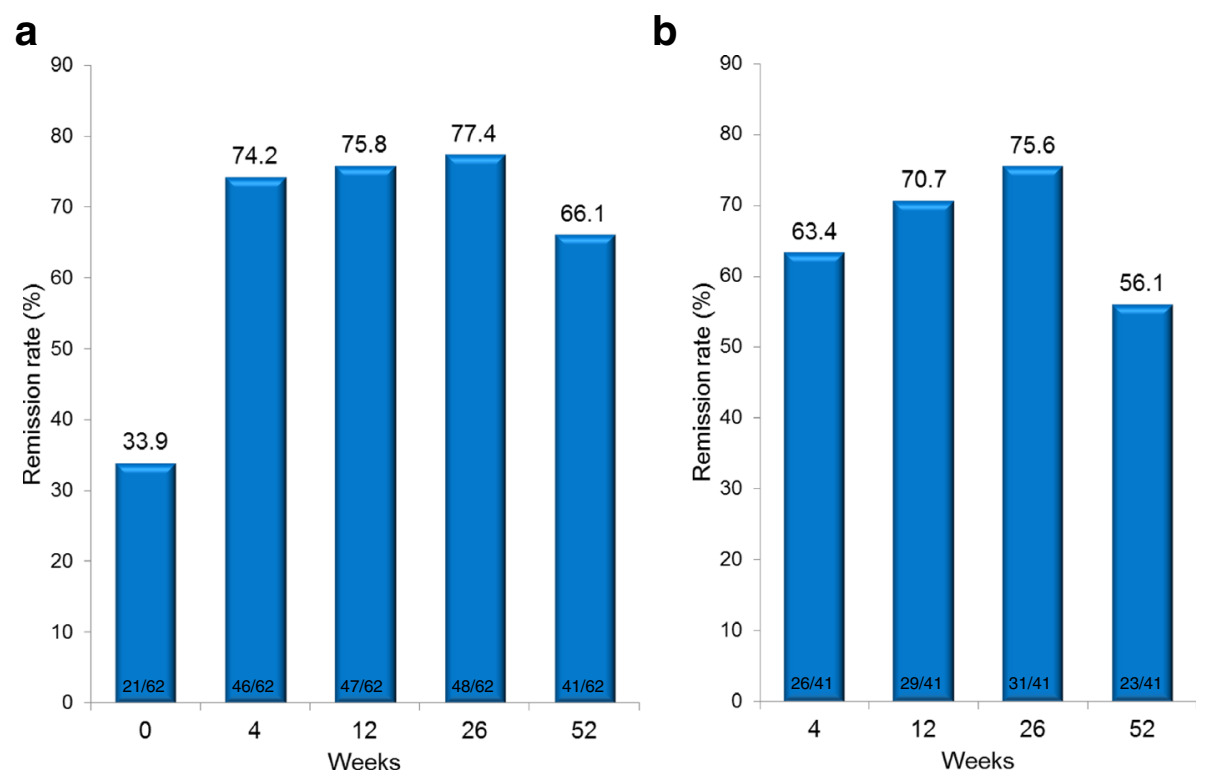

Fig. 2 Remission rate after up to 52 weeks of adalimumab treatment. The proportion of patients who achieved remission with a Crohn's Disease Activity Index (CDAl) $<150$ is shown. a Remission rate of all 62 patients. $\mathbf{b}$ Remission rate of all 41 patients with a baseline CDAl $\geq 150$. Ten patients who discontinued the study treatment were categorized into the non-remission group

nonresponse to IFX treatment, while the patient with a Rutgeerts score of i4 had all four risk factors.

\section{Safety}

In the assessment of up to 52 weeks, adverse events were reported in a total of eight patients: pancytopenia, sepsis, lupus-like reaction, hepatic function disorder, recurrent upper respiratory tract infection, ss-DNA antibody positive, catheter infection, and rash in one patient each. ADA treatment was discontinued due to adverse events in all seven patients except the one with the rash. All events were resolved under observation after ADA discontinuation or with treatment. There was no report of malignant tumor development or death.

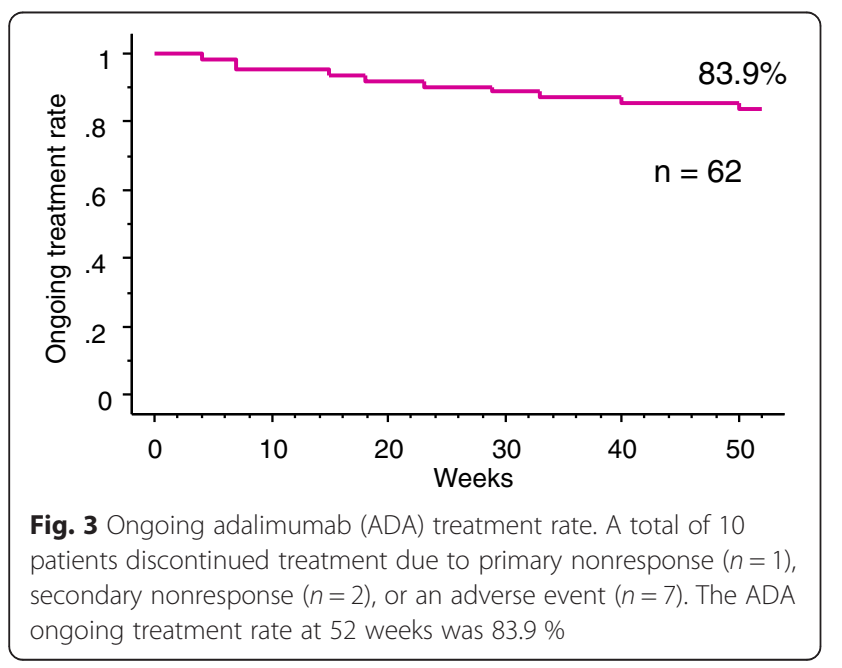

\section{Discussion}

ADA has been demonstrated effective against $C D$ in the CLASSIC I [11], CLASSIC II [13], GAIN [12], CHARM [14], and EXTEND [15] placebo-controlled double-blind studies. In Japan, its clinical efficacy was also demonstrated in a placebo-controlled double-blind study [17], and ADA has been available for clinical use since October 2010. However, limited reports to date are available on usage data in real practice settings in Japan and other Asian countries. Ishida, et al. [19] and Miyoshi, et al. [20] reported results from a single center study with limited sample sizes of 28 and 45 subjects, respectively. Therefore, we investigated the results of ADA treatment for $C D$ in real practice settings in this multicenter observational study. The remission rates from 4 to 52 weeks were similar to those reported by Ishida, et al. [19] and Miyoshi, et al [20]. ADA was more effective in real practice settings than in a clinical study with limited patients based on various exclusion criteria and a CDAI of 220-450 [17].

This study identified CD location and baseline CDAI as factors associated with ADA efficacy at 52 weeks. A study by Cohen, et al. [30] also indicated a slightly higher nonresponse rate in patients with the colonic type but with no significant difference. To our knowledge, only the current study demonstrated lower ADA efficacy in patients with the colonic type. We believe that the effects of TNF- $\alpha$ may be greater in patients with lesions in the small intestine, but no significant difference was detected on multivariate analysis, so this issue requires further investigation. Other factors including previous IFX treatment 
Table 2 Comparison of remission and non-remission groups at 52 weeks

\begin{tabular}{|c|c|c|c|}
\hline & Remission $(n=41)$ & Non-remission $(n=21)$ & $P$ value \\
\hline Age (years) & $32.1 \pm 10.5$ & $34.9 \pm 10.1$ & $0.3201^{a}$ \\
\hline Gender (male) & $75.6 \%(31 / 41)$ & $71.4 \%(15 / 21)$ & $0.7648^{c}$ \\
\hline Disease duration (months) & $87.0(0.0-480.0)$ & $144.0(0.0-336.0)$ & $0.3964^{b}$ \\
\hline Disease duration $<2$ years & $36.6 \%(15 / 41)$ & $23.8 \%(5 / 21)$ & $0.3962^{c}$ \\
\hline Colonic type & $4.9 \%(2 / 41)$ & $23.8(5 / 21)$ & ${ }^{*} 0.0387^{c}$ \\
\hline Surgery & $61.0 \%(25 / 41)$ & $66.7 \%(14 / 21)$ & $0.7837^{c}$ \\
\hline Extra fistula & $30.0 \%(12 / 40)$ & $42.9 \%(9 / 21)$ & $0.3980^{c}$ \\
\hline Intra fistula & $7.5 \%(3 / 40)$ & $9.5 \%(2 / 21)$ & $>0.9999^{c}$ \\
\hline Perianal disease & $46.3 \%(19 / 41)$ & $52.4 \%(11 / 21)$ & $0.7895^{c}$ \\
\hline Smoking & $17.6 \%(6 / 34)$ & $16.7 \%(3 / 18)$ & $>0.9999^{c}$ \\
\hline \multicolumn{4}{|l|}{ Concomitant use } \\
\hline 5-Aminosalicylates & $87.8 \%(36 / 41)$ & $100 \%(21 / 21)$ & $0.1569^{c}$ \\
\hline Steroids & $9.8 \%(4 / 41)$ & $9.5 \%(2 / 21)$ & $>0.9999^{c}$ \\
\hline Immunomodulators & $22.0 \%(9 / 41)$ & $28.6 \%(6 / 21)$ & $0.7548^{c}$ \\
\hline Elemental diet & $65.9 \%(27 / 41)$ & $57.1 \%(12 / 21)$ & $0.5829^{c}$ \\
\hline \multicolumn{4}{|l|}{ IFX experience } \\
\hline Experience with IFX & $51.2 \%(21 / 41)$ & $57.1 \%(12 / 21)$ & $0.7895^{c}$ \\
\hline Double dose & $28.6 \%(6 / 21)$ & $41.7 \%(5 / 12)$ & $0.4713^{c}$ \\
\hline Duration of IFX use (months) & $19.5(1.0-84.0)$ & $10.0(1.0-100)$ & $0.7818^{b}$ \\
\hline Reason of switch & & & $0.5700^{d}$ \\
\hline PNR & $10.0 \%(2 / 20)$ & $0.0 \%(0 / 12)$ & \\
\hline SNR & $45.0 \%(9 / 20)$ & $50.0 \%(6 / 12)$ & \\
\hline Intolerance & $40.0 \%(8 / 20)$ & $50.0 \%(6 / 12)$ & \\
\hline Other & $5.0 \%(1 / 20)$ & $0.0 \%(0 / 12)$ & \\
\hline CDAI at baseline (points) & $169.5 \pm 76.8$ & $215.4 \pm 67.2$ & ${ }^{*} 0.0236^{\mathrm{a}}$ \\
\hline CRP at baseline (mg/dL) & $0.70(0.00-6.86)$ & $0.88(0.02-6.34)$ & $0.4436^{\mathrm{b}}$ \\
\hline
\end{tabular}

Parametric variables are shown as mean \pm standard deviation or median (range)

IFX infliximab, PNR primary nonresponse, SNR secondary nonresponse, CDAI Crohn's Disease Activity Index, CRP C-reactive protein $* P<0.05$

${ }^{\text {a }}$ Student's $t$-test; ${ }^{b}$ Mann-Whitney $U$-test; ${ }^{\mathrm{C}}$ Fisher's exact test; ${ }^{\mathrm{d}}$ Chi-square test

$[31,32]$ and disease duration $[33,34]$ are reportedly associated with ADA efficacy, but this study did not show a significant difference in these factors. This may be due to an insufficient sample size and the fact that more patients had fewer disease activity events such as intolerance with previous IFX treatment. The combined effect of immunomodulator and ADA has yet to be confirmed because of conflicting reports [35-38], and no difference was noted in this study either. Thus, prospective comparative studies

Table 3 Predictors of remission at 52 weeks of adalimumab treatment (multivariate analysis)

\begin{tabular}{llc}
\hline Factor & Odds ratio $(95 \% \mathrm{Cl})$ & $P$ value \\
\hline CDAl at baseline & $0.993(0.985-1.000)$ & 0.0577 \\
Colonic type & $0.207(0.035-1.230)$ & 0.0833 \\
\hline
\end{tabular}

Cl confidence interval, CDAl Crohn's Disease Activity Index of ADA like the IFX SONIC study $[39,40]$ are needed. The combined effect of an elemental diet and IFX has also been reported [41-43], but no difference was observed in this study. Serum ADA concentration and involvement in efficacy of anti-adalimumab antibody (AAA) have been highly reported recently [44-49], but we could not evaluate these parameters in the current study.

We also investigated the ability of ADA to prevent postoperative recurrence. Several reports have been published to date in Europe or the US [25, 50-52], but there are few reports from Asian countries. This study confirmed that ADA effectively prevented postoperative recurrence in a small sample of 16 patients. While a metaanalysis indicated the efficacy of anti-TNF- $\alpha$ antibody for preventing postoperative recurrence [26], the use of antiTNF- $\alpha$ antibody has a cost-benefit performance issue [53] and is recommended for patients at high risk and those in 
Table 4 Results of ADA treatment for the prevention of postoperative recurrence

\begin{tabular}{|c|c|c|c|c|c|c|c|c|c|c|c|c|c|c|c|c|}
\hline \multicolumn{7}{|c|}{ Basic characteristic } & \multicolumn{5}{|l|}{ Risk factor } & \multicolumn{2}{|c|}{$\begin{array}{l}\text { Clinical remission } \\
\text { (last examination) }\end{array}$} & \multicolumn{3}{|c|}{ Endoscopy (last examination) } \\
\hline Patient & Gender & $\begin{array}{l}\text { Age } \\
\text { (years) }\end{array}$ & $\begin{array}{l}\text { Disease } \\
\text { duration } \\
\text { (months) }\end{array}$ & $\begin{array}{l}\text { Disease } \\
\text { location }\end{array}$ & $\begin{array}{l}\text { Previous } \\
\text { IFX }\end{array}$ & $\begin{array}{l}\text { Time to ADA } \\
\text { after resection } \\
\text { (days) }\end{array}$ & Smoking & $\begin{array}{l}\text { Penetrating } \\
\text { disease }\end{array}$ & $\begin{array}{l}\text { Previous } \\
\text { resection }\end{array}$ & $\begin{array}{l}\text { Disease } \\
\text { duration } \\
\text { (<10 years) }\end{array}$ & $\begin{array}{l}\text { Numbers } \\
\text { of risk } \\
\text { factors }\end{array}$ & $\begin{array}{l}\text { Time to last } \\
\text { examination } \\
\text { (months) }\end{array}$ & Remission & $\begin{array}{l}\text { Time to } \\
\text { Endoscopy } \\
\text { (months) }\end{array}$ & $\begin{array}{l}\text { Rutgeerts } \\
\text { score }\end{array}$ & $\begin{array}{l}\text { Mucosal } \\
\text { healing }\end{array}$ \\
\hline 1 & M & 33 & 153 & Ileocolonic & $\circ$ & 43 & $x$ & 0 & $\circ$ & $x$ & 2 & 48 & $\circ$ & 20 & i0 & $\circ$ \\
\hline 2 & M & 32 & 77 & Ileocolonic & $\circ$ & 18 & $\circ$ & ० & $\circ$ & $\circ$ & 4 & 50 & $\circ$ & 44 & i4 & $x$ \\
\hline 3 & M & 38 & 96 & Ileocolonic & $x$ & 23 & $\circ$ & ० & $x$ & $\circ$ & 3 & 49 & $\circ$ & 47 & i0 & $\circ$ \\
\hline 4 & M & 30 & 178 & lleo & $\circ$ & 57 & $x$ & $\circ$ & $\circ$ & $x$ & 2 & 46 & $x$ & 37 & i3 & $x$ \\
\hline 5 & M & 29 & 3 & Ileocolonic & $\times$ & 40 & $\circ$ & $x$ & $x$ & ० & 2 & 40 & $\circ$ & 28 & i2 & $\times$ \\
\hline 6 & M & 50 & 276 & lleo & $x$ & 49 & $x$ & $x$ & $\circ$ & $x$ & 1 & 32 & $\circ$ & 23 & i0 & o \\
\hline 7 & M & 19 & 8 & Ileocolonic & $x$ & 15 & $\circ$ & $x$ & $x$ & $\circ$ & 2 & 38 & $\circ$ & 22 & i0 & $\circ$ \\
\hline 8 & M & 50 & 480 & Ileocolonic & $\circ$ & 23 & $x$ & o & $\circ$ & $\times$ & 2 & 38 & $\circ$ & 38 & i1 & o \\
\hline 9 & M & 34 & 180 & Ileo & $\circ$ & 60 & $\circ$ & $\times$ & $\circ$ & $x$ & 2 & 31 & $\circ$ & 8 & i0 & o \\
\hline 10 & M & 33 & 120 & lleo & $x$ & 240 & $x$ & ० & $x$ & $\circ$ & 2 & 29 & $\circ$ & 28 & i2 & $x$ \\
\hline 11 & M & 43 & 204 & Ileocolonic & $\times$ & 73 & $\times$ & o & $\circ$ & $\times$ & 2 & 32 & $\circ$ & - & - & - \\
\hline 12 & M & 47 & 36 & Ileocolonic & $x$ & 53 & $x$ & ० & $\circ$ & ० & 3 & 24 & $\circ$ & - & - & - \\
\hline 13 & M & 23 & 18 & Ileocolonic & $x$ & 22 & $x$ & ० & $x$ & $\circ$ & 2 & 15 & $\circ$ & 8 & i0 & $\circ$ \\
\hline 14 & $\mathrm{~F}$ & 45 & 396 & Ileocolonic & $x$ & 82 & $x$ & ० & $\circ$ & $x$ & 2 & 24 & $\circ$ & 24 & i3 & $x$ \\
\hline 15 & M & 27 & 3 & Ileocolonic & $x$ & 10 & $x$ & $\times$ & $x$ & $\circ$ & 1 & 16 & $\circ$ & 15 & i0 & ० \\
\hline 16 & $\mathrm{~F}$ & 31 & 18 & Ileocolonic & $x$ & 38 & $x$ & ० & $x$ & $\circ$ & 2 & 12 & $\circ$ & 12 & i0 & $\circ$ \\
\hline Total & $\begin{array}{l}\text { M/F: } \\
14 / 2\end{array}$ & 35.3 & 140.4 & $4 / 12$ & $\begin{array}{l}31.3 \% \text { (5/ } \\
16)\end{array}$ & 52.9 & $\begin{array}{l}31.3 \% \text { (5/ } \\
16)\end{array}$ & $\begin{array}{l}68.8 \%(11 / \\
16)\end{array}$ & $\begin{array}{l}56.3 \%(9 / \\
16)\end{array}$ & $\begin{array}{l}56.3 \%(9 / \\
16)\end{array}$ & 2.1 & 32.3 & $\begin{array}{l}93.8 \% \\
(15 / 16)\end{array}$ & 25.3 & - & $\begin{array}{l}64.3 \%(9 / \\
14)\end{array}$ \\
\hline
\end{tabular}

Parametric variables as total are shown as mean or rates

$A D A$ adalimumab, IFX infliximab 
whom relapse was observed in postoperative monitoring [54]. The POCER study recently reported on the usefulness of postoperative risk factor-based therapeutic stratification, endoscopic monitoring, and therapeutic intensification [55]. However, in the POCER study, thiopurine was used as the first-line treatment even for highrisk patients, while the active care group with endoscopic evaluation and therapeutic intensification had a relatively high recurrence rate. A greater number of risk factors was associated with a higher relapse rate. Our study also indicated more risk factors in patients who showed endoscopic recurrence with a Rutgeerts score of i3 or i4. Therefore, positive use of anti-TNF- $\alpha$ antibody may require consideration for high-risk patients. Recent studies reported the usefulness of fecal calprotectin as a parameter in postoperative monitoring [56, 57]. Postoperative monitoring and therapeutic optimization as considerations of the burden of examination and cost-benefit relationship are required.

This study has several limitations. First, it had an insufficient sample size of unselected patients with heterogeneous baseline characteristics in a real practice setting. Therefore, it was difficult to determine the efficacyassociated factors. Second, the assessment of prevention of postoperative recurrence was made only in a small group of 16 patients, the timing of ADA introduction and endoscopic examination was inconsistent, and endoscopy was not performed for some patients. Therefore, further larger-scale studies with strict evaluation methods are required to validate our results.

\section{Conclusions}

Even with the above-mentioned limitations, we concluded in this study that ADA effectively provided clinical remission and prevented postoperative recurrence of $\mathrm{CD}$ in real practice settings.

\section{Abbreviations}

AAA, anti-adalimumab antibody; ADA, adalimumab; anti-TNF-a antibody, anti-TNF-a monoclonal antibody; CD, Crohn's disease; CDAl, CD Activity Index; CRP, C-reactive protein; IBD, inflammatory bowel disease; IFX, infliximab; PNR, primary nonresponse; SNR, secondary nonresponse; TNF-a, tumor necrosis factor-a.

\section{Funding}

Funding for editorial assistance was provided by Eisai Co., Ltd.

\section{Availability of data and materials}

The data will not be made available in order to protect the anonyms.

\section{Authors' contributions}

FT participated in the study design, data collection, data analysis, and manuscript drafting and revision processes. DY, SH, TM, HO, MI, HM, KM, HM, $Y A, N Y, K O$, and $H I$ participated in the data collection process. MU participated in manuscript drafting and revision process. KN gave final approval of the

manuscript to be published. All authors read and approved the final manuscript.

\section{Competing interests}

Fuminao Takeshima and Kazuhiko Nakao received grants and lecture fees from Eisai Co., Ltd. The other authors have nothing to declare. Eisai Co., Ltd. supported the manuscript drafting and publication charge payment for this article but had no influence on the study design or results.

Consent for publication

Not applicable.

Ethics approval and consent to participate

This study was reviewed and approved by the Nagasaki University Hospital Ethics Committee.

\section{Author details}

${ }^{1}$ Department of Gastroenterology and Hepatology, Graduate School of Biomedical Science, Nagasaki University Hospital, 1-7-1 Sakamoto, Nagasaki City, Nagasaki 852-8501, Japan. ${ }^{2}$ Department of Gastroenterology and Hepatology, Sasebo City General Hospital, 9-3 Hirase-cho, Sasebo City, Nagasaki 857-8511, Japan. ${ }^{3}$ Department of Gastroenterology, National Hospital Organization Nagasaki Medical Center, 2-1001-1 Kubara, Ohmura City, Nagasaki 856-8562, Japan. ${ }^{4}$ Department of Gastroenterology and Hepatology, National Hospital Organization Ureshino Medical Center, 2436 Ureshino-cho, Ureshino City, Saga 843-0393, Japan. ${ }^{5}$ Department of Gastroenterology and Hepatology, Sasebo Chuo Hospital, 15 Yamato-cho, Sasebo City, Nagasaki 857-1195, Japan. ${ }^{6}$ Department of Internal Medicine, Kouseikai Hospital, 1-3-12 Hayama, Nagasaki City, Nagasaki 852-8053, Japan. ${ }^{7}$ Department of Internal Medicine, Shunkaikai Inoue Hospital, 6-12

Takara-machi, Nagasaki City, Nagasaki 850-0045, Japan. ${ }^{8}$ Integrated Marketing

Department, Eisai Co., Ltd., 13-1 Nishigoken-cho, Shinjuku-ku, Tokyo

162-0812, Japan.

Received: 19 November 2015 Accepted: 26 July 2016

Published online: 29 July 2016

\section{References}

1. Cosnes J, Gower-Rousseau C, Seksik P, et al. Epidemiology and natural history of inflammatory bowel diseases. Gastroenterology. 2011;140:1785-94.

2. Cosnes J, Cattan S, Blain A, et al. Long-term evolution of disease behavior of Crohn's disease. Inflamm Bowel Dis. 2002:8:244-50.

3. Pariente B, Cosnes J, Danese S, et al. Development of the Crohn's disease digestive damage score, the Lémann score. Inflamm Bowel Dis. 2011;17:1415-22.

4. Matsumoto T, Yanai S, Toya Y, et al. Internet-orientated Assessment of QOL and Actual Treatment Status in Japanese Patients with Inflammatory Bowel Disease: The 31 survey. J Crohns Colitis. 2015;9:477-82.

5. Van Deventer SJ. Tumour necrosis factor and Crohn's disease. Gut. 1997:40:443-8.

6. Hazlewood GS, Rezaie A, Borman M, et al. Comparative effectiveness of immunosuppressants and biologics for inducing and maintaining remission in Crohn's disease: a network meta-analysis. Gastroenterology. 2015;148:344-54.

7. Stidham RW, Lee TC, Higgins PD, et al. Systematic review with network meta-analysis: the efficacy of anti-TNF agents for the treatment of Crohn's disease. Aliment Pharmacol Ther. 2014;39:1349-62.

8. Targan SR, Hanauer SB, van Deventer SJ, et al. A short-term study of chimeric monoclonal antibody CA2 to tumor necrosis factor alpha for Crohn's disease Crohn's Disease cA2 Study Group. N Engl J Med. 1997;337:1029-35.

9. Hanauer SB, Feagan BG, Lichtenstein GR, et al. Maintenance infliximab for Crohn's disease: the ACCENT I randomised trial. Lancet. 2002;359:1541-9.

10. Sands $\mathrm{BE}$, Anderson FH, Bernstein $\mathrm{CN}$, et al. Infliximab maintenance therapy for fistulizing Crohn's disease. N Engl J Med. 2004;350:876-85.

11. Hanauer SB, Sandborn WJ, Rutgeerts P, et al. Human anti-tumor necrosis factor monoclonal antibody (adalimumab) in Crohn's disease: the CLASSIC-I trial. Gastroenterology. 2006;130:323-32.

12. Sandborn WJ, Rutgeerts $P$, Enns R, et al. Adalimumab induction therapy for Crohn disease previously treated with infliximab: a randomized trial. Ann Intern Med. 2007;146:829-38.

13. Sandborn WJ, Hanauer SB, Rutgeerts $P$, et al. Adalimumab for maintenance treatment of Crohn's disease: results of the CLASSIC II trial. Gut. 2007;56:1232-9.

14. Colombel JF, Sandborn WJ, Rutgeerts P, et al. Adalimumab for maintenance of clinical response and remission in patients with Crohn's disease: the CHARM trial. Gastroenterology. 2007;132:52-65.

15. Rutgeerts $P, \operatorname{Van}$ Assche $G$, Sandborn WJ, et al. Adalimumab induces and maintains mucosal healing in patients with Crohn's disease: data from the EXTEND trial. Gastroenterology. 2012;142:1102-11. 
16. Ng SC. Emerging leadership lecture: Inflammatory bowel disease in Asia: Emergence of a "Western" disease. J Gastroenterol Hepatol. 2015;30:440-5.

17. Watanabe M, Hibi T, Lomax KG, et al. Adalimumab for the induction and maintenance of clinical remission in Japanese patients with Crohn's disease. J Crohns Colitis. 2012;6:160-73.

18. Watanabe M, Hibi T, Mostafa NM, et al. Long-term safety and efficacy of adalimumab in Japanese patients with moderate to severe Crohn's disease. J Crohns Colitis. 2014;8:1407-16.

19. Ishida K, Inoue T, Fujiwara K, et al. Clinical effects of adalimumab treatment with concomitant azathioprine in Japanese Crohn's disease patients. World J Gastroenterol. 2013;19:2676-82.

20. Miyoshi J, Hisamatsu T, Matsuoka K, et al. Early intervention with adalimumab may contribute to favorable clinical efficacy in patients with Crohn's disease. Digestion. 2014;90:130-6.

21. Munkholm $P$, Langholz E, Davidsen $M$, et al. Intestinal cancer risk and mortality in patients with Crohn's disease. Gastroenterology. 1993;105:1716-23.

22. Frolkis $A D$, Lipton DS, Fiest KM, et al. Cumulative incidence of second intestinal resection in Crohn's disease: a systematic review and meta-analysis of population-based studies. Am J Gastroenterol. 2014;109:1739-48.

23. Regueiro M, Schraut W, Baidoo L, et al. Infliximab prevents Crohn's disease recurrence after ileal resection. Gastroenterology. 2009;136:441-50.

24. Yoshida $K$, Fukunaga $K$, Ikeuchi $H$, et al. Scheduled infliximab monotherapy to prevent recurrence of Crohn's disease following ileocolic or ileal resection: a 3-year prospective randomized open trial. Inflamm Bowel Dis. 2012:18:1617-23.

25. Savarino E, Bodini G, Dulbecco $P$, et al. Adalimumab is more effective than azathioprine and mesalamine at preventing postoperative recurrence of Crohn's disease: a randomized controlled trial. Am J Gastroenterol. 2013;108:1731-42.

26. Singh S, Garg SK, Pardi DS, et al. Comparative efficacy of pharmacologic interventions in preventing relapse of Crohn's disease after surgery: a systematic review and network meta-analysis. Gastroenterology. 2015;148:64-76.

27. Best WR, Becktel JM, Singleton JW, Kern Jr F. Development of a Crohn's disease activity index. National Cooperative Crohn's Disease Study. Gastroenterology. 1976;70:439-44.

28. Schwartz M, Regueiro M. Prevention and treatment of postoperative Crohn's disease recurrence: an update for a new decade. Curr Gastroenterol Rep. 2011;13:95-100.

29. Rutgeerts P, Geboes K, Vantrappen G, et al. Predictability of the postoperative course of Crohn's disease. Gastroenterology. 1990;99:956-63.

30. Cohen $\mathrm{RD}$, Lewis JR, Turner $\mathrm{H}$, et al. Predictors of adalimumab dose escalation in patients with Crohn's disease at a tertiary referral center. Inflamm Bowel Dis. 2012;18:10-6.

31. Chaparro M, Panés J, García $V$, et al. Long-term durability of response to adalimumab in Crohn's disease. Inflamm Bowel Dis. 2012;18:685-90.

32. Löfberg R, Louis EV, Reinisch W, et al. Adalimumab produces clinical remission and reduces extraintestinal manifestations in Crohn's disease: results from CARE. Inflamm Bowel Dis. 2012;18:1-9.

33. Schreiber S, Reinisch W, Colombel JF, et al. Subgroup analysis of the placebo-controlled CHARM trial: increased remission rates through 3 years for adalimumab-treated patients with early Crohn's disease. J Crohns Colitis. 2013;7:213-21

34. Peters CP, Eshuis EJ, Toxopeüs FM, et al. Adalimumab for Crohn's disease: long-term sustained benefit in a population-based cohort of 438 patients. J Crohns Colitis. 2014:8:866-75.

35. Kopylov U, Al-Taweel T, Yaghoobi M, et al. Adalimumab monotherapy versus combination therapy with immunomodulators in patients with Crohn's disease: a systematic review and meta-analysis. J Crohns Colitis. 2014;8:1632-41.

36. Reenaers C, Louis E, Belaiche J, et al. Does co-treatment with immunosuppressors improve outcome in patients with Crohn's disease treated with adalimumab? Aliment Pharmacol Ther. 2012;36:1040-8.

37. Kestens $C$, van Oijen $M G$, Mulder $C L$, et al. Adalimumab and infliximab are equally effective for Crohn's disease in patients not previously treated with anti-tumor necrosis factor-a agents. Clin Gastroenterol Hepatol. 2013;11:826-31.

38. van Schaik T, Maljaars JP, Roopram RK, et al. Influence of combination therapy with immune modulators on anti-TNF trough levels and antibodies in patients with IBD. Inflamm Bowel Dis. 2014;20:2292-8.

39. Colombel JF, Sandborn WJ, Reinisch W, et al. Infliximab, azathioprine, or combination therapy for Crohn's disease. N Engl J Med. 2010;362:1383-95.
40. Colombel JF, Reinisch W, Mantzaris GJ, et al. Randomised clinical trial: deep remission in biologic and immunomodulator naïve patients with Crohn's disease - a SONIC post hoc analysis. Aliment Pharmacol Ther. 2015;41:734-46.

41. Hirai $F$, Ishihara $H$, Yada $S$, et al. Effectiveness of concomitant enteral nutrition therapy and infliximab for maintenance treatment of Crohn's disease in adults. Dig Dis Sci. 2013;58:1329-34.

42. Sazuka S, Katsuno T, Nakagawa T, et al. Concomitant use of enteral nutrition therapy is associated with sustained response to infliximab in patients with Crohn's disease. Eur J Clin Nutr. 2012;66:1219-23.

43. Kamata N, Oshitani N, Watanabe K, et al. Efficacy of Concomitant Elemental Diet Therapy in Scheduled Infliximab Therapy in Patients with Crohn's Disease to Prevent Loss of Response. Dig Dis Sci. 2015;60:1382-8.

44. Karmiris K, Paintaud G, Noman M, et al. Influence of trough serum levels and immunogenicity on long-term outcome of adalimumab therapy in Crohn's disease. Gastroenterology. 2009;137:1628-40.

45. Baert F, Kondragunta V, Lockton S, et al. Antibodies to adalimumab are associated with future inflammation in Crohn's patients receiving maintenance adalimumab therapy: a post hoc analysis of the Karmiris trial. Gut. 2016;65:1126-31.

46. Mazor Y, Almog R, Kopylov U, et al. Adalimumab drug and antibody levels as predictors of clinical and laboratory response in patients with Crohn's disease. Aliment Pharmacol Ther. 2014;40:620-8.

47. Imaeda H, Takahashi K, Fujimoto T, et al. Clinical utility of newly developed immunoassays for serum concentrations of adalimumab and anti-adalimumab antibodies in patients with Crohn's disease. J Gastroenterol. 2014;49:100-9.

48. Roblin X, Marotte $H$, Rinaudo M, et al. Association between pharmacokinetics of adalimumab and mucosal healing in patients with inflammatory bowel diseases. Clin Gastroenterol Hepatol. 2014;12:80-4.

49. Paul S, Moreau AC, Del Tedesco E, et al. Pharmacokinetics of adalimumab in inflammatory bowel diseases: a systematic review and meta-analysis. Inflamm Bowel Dis. 2014;20:1288-95.

50. Papamichael K, Archavlis E, Lariou C, et al. Adalimumab for the prevention and/or treatment of post-operative recurrence of Crohn's disease: a prospective, two-year, single center, pilot study. J Crohns Colitis. 2012;6:924-31.

51. Aguas M, Bastida G, Cerrillo E, et al. Adalimumab in prevention of postoperative recurrence of Crohn's disease in high-risk patients. World J Gastroenterol. 2012;18:4391-8.

52. Savarino E, Dulbecco P, Bodini G, et al. Prevention of postoperative recurrence of Crohn's disease by Adalimumab: a case series. Eur J Gastroenterol Hepatol. 2012;24:468-70.

53. Ananthakrishnan AN, Hur C, Juillerat $P$, et al. Strategies for the prevention of postoperative recurrence in Crohn's disease: results of a decision analysis. Am J Gastroenterol. 2011;106:2009-17.

54. De Cruz $P$, Kamm MA, Prideaux $L$, et al. Postoperative recurrent luminal Crohn's disease: a systematic review. Inflamm Bowel Dis. 2012;18:758-77.

55. De Cruz P, Kamm MA, Hamilton AL, et al. Crohn's disease management after intestinal resection: a randomised trial. Lancet. 2015;385:1406-17.

56. Wright EK, Kamm MA, De Cruz P, et al. Measurement of Fecal Calprotectin Improves Monitoring and Detection of Recurrence of Crohn's Disease After Surgery. Gastroenterology. 2015;148:938-47.

57. Boschetti G, Laidet M, Moussata D, et al. Levels of Fecal Calprotectin Are Associated With the Severity of Postoperative Endoscopic Recurrence in Asymptomatic Patients With Crohn's Disease. Am J Gastroenterol. 2015;110:865-72

\section{Submit your next manuscript to BioMed Central and we will help you at every step:}

- We accept pre-submission inquiries

- Our selector tool helps you to find the most relevant journal

- We provide round the clock customer support

- Convenient online submission

- Thorough peer review

- Inclusion in PubMed and all major indexing services

- Maximum visibility for your research

Submit your manuscript at www.biomedcentral.com/submit 